\title{
Books received - Livres reçus - Eingegangene Bücher
}

BONIN Hubert, Les entreprises et l'outre-mer français pendant la Seconde Guerre mondiale, MSHA, Bordeaux, 2010, 353 p. - ISBN 978-2-85892-366-3 - 26,00 €.

BONIN Hubert, History of the Suez Canal Company 1858-2008 Between Controversy and Utility, Droz, Genève, 2010, 573 p. - ISBN 978-2-600-01331-4 - 56,05 €.

BOSSUAT Gérard, BUSSIÈRE Éric, FRANK Robert, LOTH Wilfried, VARSORI Antonio (dir.), L'expérience européenne 50 ans de construction de l'Europe 1957-2007 des historiens en dialogue, Actes du colloque international de Rome 2007, Bruylant, Bruxelles, 2010, 510 p. - ISBN 978-2-8027-2780-4 - 65,00 €.

EBERT Volker, Korporatismus zwischen Bonn und Brüssel, Die Beteiligung deutscher Unternehmensverbände an der Güterverkehrspolitik (1957-1972), Franz Steiner Verlag, Stuttgart, 2010, 452 S. - ISBN 978-3-515-09692-8 - 68,00 €.

EBERT Volker, HARTER Philipp-Alexander, Europa ohne Fahrplan?, Franz Steiner Verlag, 2010, 278 S. - ISBN 978-3-515-09693-5 - 52,00 €.

FELTEN Franz J., Frankreich am Rhein - vom Mittelalter bis heute, Franz Steiner Verlag, Stuttgart, 2009, 236 S. - ISBN 978-3-515-09327-9-29,00€.

GEGOUT Catherine, European Foreign and Security Policy, University of Toronto Press, Toronto, 2010, 266 p. - ISBN 978-1-4426-1034-7 - 27,95 \$.

KREUTZFELDT Jens, "Point of return”. Großbritannien und die Politische Union Europas 1969-1975, Franz Steiner Verlag, Stuttgart, 2010, 650 S. - ISBN 978-3-515-09722-2-72,00€.

MAES Ivo, A century of macroeconomic and monetary thought at the National Bank of Belgium, National Bank of Belgium, Brussels, 2010, 154 p. - ISBN $9789078834045-$ ?

MEYER Jan-Henrik, The European Public Sphere, Franz Steiner Verlag, Stuttgart, 2010, 361 p. - ISBN 978-3-515-09649-2 - 49,00€.

MONTARSOLO Yves, L'Eurafrique contrepoint de l'idée d'Europe, Publications de l'Université de Provence, Aix-en-Provence, 2010, 297 p. - ISBN 978-2-85399-728-7-27,00€.

SEIDEL Katja, The process of Politics in Europe: The Rise of European Elites and Supranational Institutions, I.B. Tauris publishers, London, 2010, 245 p. - ISBN 978-1-84885-326-3-68,16€. 
VAHSEN Urban, Eurafrikanische Entwicklungskooperation, Franz Steiner Verlag, Stuttgart, 2010, 420 S. ISBN - 978-3-515-09667-6 - 52,00 €.

VARSORI Antonio, La cenerentola d'Europa? L'Italia e l'integrazione Europea dal 1947 a oggi, Rubbettino, Soveria Mannelli, 2010, 473 p. ISBN 978-88-498-2589-3-28,00€. 